\title{
Novos assinalamentos de nematóides de parte aérea (Aphelenchoides spp.) em plantas de begônia no Brasil
}

\author{
CLAUDIO MARCELO G. OLIVEIRA(1) e ROBERTO K. KUBO(1)
}

\section{RESUMO}

\begin{abstract}
Os nematóides da parte aérea, Aphelenchoides besseyi e A. ritzemabosi, foram detectados causando lesões pardo-escuras em todo o limbo foliar de plantas de begônia (Begonia sp.) no Brasil. Trata-se da primeira ocorrência de A. besseyi parasitando essa planta ornamental.
\end{abstract}

Palavras-chave: Aphelenchoides besseyi, A. ritzemabosi, planta ornamental.

\begin{abstract}
Foliar nematodes (Aphelenchoides spp.) on begonia in Brazil. The foliar nematodes Aphelenchoides besseyi and A. ritzemabosi were reported causing dark brown lesions on begonia leaves in Brazil. It is the first report of $A$. besseyi parasiting this ornamental plant.
\end{abstract}

Key words: Aphelenchoides besseyi, A. ritzemabosi, ornamental plant.

\section{INTRODUÇÃO}

Os nematóides que causam danos às plantas ornamentais podem afetar todas as suas partes, principalmente os órgãos subterrâneos (raízes, rizomas, tubérculos e bulbos). No entanto, diferentemente dos outros grupos, algumas espécies de nematóides do gênero Aphelenchoides são parasitas obrigatórias de órgãos aéreos. Esses nematóides movimentam-se pelo limbo foliar por uma fina película de água, penetram pelos estômatos ou algum ferimento, alimentando-se de tecidos foliares, agindo como endoparasitos e causando lesões. Também podem atuar como ectoparasitos, alimentando-se dos brotos e promovendo deformações. Em geral, as folhas atacadas têm coloração anormal, necrose e tamanho reduzido, depreciando a qualidade do produto a ser comercializado(HUNT, 1993).

As principais espécies desse gênero associadas às plantas ornamentais no Brasil são Aphelenchoides fragariae, relatada parasitando Asplenium nidus e Dyzygotheca castor variegata; $A$. besseyi, detectado no substrato, raiz e folhas de Calathea openheiminiana, além de $A$. ritzemabosi, agente causal de danos em Chrysanthemum morifolium e Begonia $x$ hiemalis (SILVEIRA et al., 1986; COSTA MANSO et al., 1994; OLIVEIRA, 2001).

Apesar de sua importância econômica devido aos prejuízos causados, as informações relacionadas aos nematóides de parte aérea em plantas ornamentais no Brasil são escassas. Por exemplo, CURI \& PITTA (1971) observaram alta infestação de $A$. ritzemabosi em folhas de crisântemo (Chrysanthemum sp.). Os sintomas caracterizavam-se pela presença de manchas castanhas ou pardas, delimitadas pelas nervuras das folhas, enquanto as flores eram escuras e secas. Ademais, ROSSI \&
MONTEIRO (1995) já haviam relatado o ataque generalizado de A. ritzemabosi (aproximadamente 277.500 nematóides por $10 \mathrm{~g}$ de folhas) em plantas de begônia Rieder (Begonia x hiemalis Fotsch) cultivadas em estufas nas regiões de Salesópolis e de Campinas(SP), exibindo lesões pardo-escuras nas bordas das folhas ou em todo o limbo foliar.

Recentemente, plantas de begônia, provenientes de Artur Nogueira e Jacareí (SP), foram encaminhadas ao Instituto Biológico para análise nematológica. As plantas tinham porte reduzido e anomalias foliares. Os agentes causais foram identificados como os nematóides Aphelenchoides besseyi e A. ritzemabosi. Dessa forma, ao lado de registrar tais ocorrências, objetivou-se neste trabalho caracterizar e ilustrar os sintomas das nematoses verificadas em begônias cultivadas nesses municípios do Estado de São Paulo.

\section{MATERIALEMÉTODOS}

Os nematóides foram extraídos pelo método de COOLEN \& D'HERDE (1972) a partir de amostras de 10 $\mathrm{g}$ de folhas de begônia (Begonia sp.). Posteriormente, foram estimadas as densidades populacionais. Para tanto, o volume da suspensão foi reduzido por sifonamento a $10 \mathrm{~cm}^{3}$ e uma alíquota de $1 \mathrm{~cm}^{3}$ foi utilizada para a contagem dos nematóides presentes, em lâminas de Peters, sob microscópio. Lâminas temporárias em formalina $2 \%$ foram montadas visando à identificação das espécies presentes, com base nas características taxonômicas descritas por HUNT (1993) - forma da região labial, número de linhas do campo lateral, comprimento do ramo uterino posterior e forma da cauda - e por meio da chave dicotômica proposta por SANWAL (1961).

(1) Instituto Biológico, Caixa Postal 70, 13001-970, Campinas (SP) Brasil 


\section{RESULTADOS E DISCUSSÃO}

Com base nas características morfológicas observadas ao microscópio óptico, identificou-se, como agente causal dos sintomas observados nas folhas das plantas provenientes de Artur Nogueira, o nematóide Aphelenchoides besseyi (aproximadamente 2100 nematóides por $10 \mathrm{~g}$ de folhas). De acordo com a literatura disponível, trata-se da primeira ocorrência dessa espécie em begônia.

Com relação ao material proveniente de Jacareí(SP), o nematóide foi identificado como A. ritzemabosi (aproximadamente 38.000 nematóides por $10 \mathrm{~g}$ de folhas), similar ao relato anterior de ROSSI \& MONTEIRO (1995), inclusive os sintomas, caracterizado inicialmente pela presença de lesões pardo-escuras nas bordas das folhas e necroses em todo o limbo foliar, num estágio mais avançado do parasitismo (figura 1).

A partir das identificações do presente trabalho e das informações disponíveis na literatura nacional, elaborouse a tabela 1 , sumariando as ocorrências de espécies de Aphelenchoides em plantas ornamentais no Brasil.

Lâminas contendo os espécimes de $A$. bessey e $A$. ritzemabosi encontram-se depositadas no Laboratório de Nematologia do Centro Experimental Central do Instituto Biológico sob número CM 06/05 e SN82/97, respectivamente.

\section{REFERÊNCIAS}

CARVALHO, J.C. Aphelenchoides coffeae em raízes de gerânio. Revista do Instituto Adolfo Lutz, São Paulo, v. 13, p.33-36, 1953 .

CESNIK, R. Nematodeos que parasitam a gloxínia (Sinningia speciosa). Revista de Agricultura, Piracicaba, v.34, n.2, p.131-138, 1959.

COOLEN, W.A. \& D'HERDE, C.J. A method for the quantitative extraction of nematodes from plant tissue. Ghent: State Nematology and Entomology Research Station, $1972.77 \mathrm{p}$.

COSTAMANSO, E., TENENTE, R.C.V., FERRAZ, L.C.C.B., OLIVEIRA, R.S. \& MESQUITA, R. Catálogo de nematóides fitoparasitos encontrados associados a diferentes tipos de plantas no Brasil. Brasília: Embrapa-SPI, 1994. 488p.

CURI, S.M. \& PITTA, G.P.B. Ocorrência do nematóide das folhas do crisântemo, Aphelenchoides ritzemabosi (Schwartz, 1911) Steiner, 1932 no Estado de São Paulo. Biológico, São Paulo, v.38, n.4, p.127-128, 1971.
CURI S.M. \& SILVEIRA S.G.P. Nematóides (Aphelenchoides bicaudatus, A. besseyi e Ditylenchus myceliophagus) associados a Calathea spp. Nematologia Brasileira, Piracicaba, v.14, p.3-4, 1990.

FERRAZ, S. Reconhecimento das espécies de fitonematóides presentes nos solos do Estado de Minas Gerais. Experientiae, Viçosa, v.26, n.11, p.255-328, 1980.

HUANG, C.S. Ocorrência de Aphelenchoides fragariae em Asplenium nidus no Estado do Rio de Janeiro. Fitopatologia Brasileira, v.7, n.3, p.568, 1982.

HUANG C.S., SILVA, C.B., SILVA, G.S., ARAÚJO, J.C.A. \& GARCIA, E.S.C.B. Nematóides fitoparasitos encontrados na ilha de São Luiz e município de Rosário do Estado do Maranhão. In: REUNIÃO BRASILEIRA DE NEMATOLOGIA, 6, 1982,. Resumos... Fortaleza, 1982, p.39.

HUNT, D.J. Aphelenchida, Longidoridae and Trichodoridae: their systematics and bionomics. Wallingford: CABI Publishing, 1993.352p.

OLIVEIRA, C.M.G. Nematóides parasitos de plantas. In: IMENES, S.L. \& ALEXANDRE, M.A.V. (Eds.) Pragas e doenças em plantas ornamentais, CD-ROM (ISBN 8588694-01-8). São Paulo: Instituto Biológico, 2001. p. 38-47.

ROSSI, C.E. \& MONTEIRO, A.R. Begônia Rieger: novo hospedeiro de Aphelenchoides ritzemabosi no Estado de São Paulo. Revista de Agricultura, Piracicaba, v.70, n.3, p.311-313, 1995.

SANWAL, K.C. A key to the species of the nematode genus Aphelenchoides Fischer, 1894. Canadian Journal of Zoology, Ottawa, v.39, p.143-148, 1961.

SHARMA, R.D. Nematodes of the cocoa region of Bahia, Brazil: VII Nematodes associated with some ornamental plants. Sociedade Brasileira Nematologia, Piracicaba, v.2, p.135-137, 1977.

SILVA, L. Detecção de Aphelenchoides sp. em plantas de Chrysanthemum sp, cultivadas no município de Terra de Areia, RS. Nematologia Brasileira, Piracicaba, v.18, n. 1/2, p.12, 1994.

SILVEIRA, S.G.P., CURI, S.M. \& STEFANINI, P.C. Nematóides de plantas detectados pela Seção de Nematologia do Instituto Biológico de São Paulo, Brasil. Biológico, São Paulo, v.52, p.91-104, 1986.

SILVEIRA, S.G.P., CURI, S.M., RAMOS, R.S. \& SINIGAGLIA, C. Ocorrência do nematóide Aphelenchoides bicaudatus em cebola e $A$. composticola em orquídea. Nematologia Brasileira, Piracicaba, v.16, p.89, 1992. 
Tabela 1. Espécies de Aphelenchoides associadas a plantas ornamentais no Brasil. Table 1. Aphelenchoides species associated to ornamental plants in Brazil.

\begin{tabular}{|c|c|c|}
\hline Espécies de Aphelenchoides & Plantas ornamentais & Referência \\
\hline \multirow[t]{3}{*}{ A. besseyi } & Calathea openheiminiana & CURI \& SILVEIRA (1990) \\
\hline & Begonia sp. & presente estudo \\
\hline & Saintpaulia ionantha & OLIVEIRA (2001) \\
\hline \multirow[t]{2}{*}{ A. bicaudatus } & Calathea openheiminiana & CURI \& SILVEIRA (1990) \\
\hline & Dyzygotheca castor variegata & OLIVEIRA (2001) \\
\hline A. coffeae & Pelargonium sp. & CARVALHO (1953) \\
\hline \multirow[t]{2}{*}{ A. composticola } & Cattleya sp. & SILVEIRA et al. (1992) \\
\hline & Laelia tenebrosa, & SILVEIRA et al. (1992) \\
\hline \multirow[t]{2}{*}{ A. fragariae } & Asplenium nidus & HUANG (1982) \\
\hline & Dyzygotheca castor variegata & OLIVEIRA (2001) \\
\hline \multirow[t]{4}{*}{ A. ritzemabosi } & Begonia $\mathrm{x}$ hiemalis & ROSSI \& MONTEIRO (1995) \\
\hline & Begonia sp. & presente estudo \\
\hline & Chrysanthemum morifolium & CURI \& PITTA (1971) \\
\hline & Chrysanthemum sp. & SHARMA (1977) \\
\hline \multirow[t]{7}{*}{ Aphelenchoides sp. } & Chrysanthemum sp. & SILVA (1994) \\
\hline & Gladiolus grandiflorus & SILVEIRA et al. (1986) \\
\hline & Polypodium sp. & SILVEIRA et al. (1986) \\
\hline & Rosa sp. & FERRAZ (1980) \\
\hline & Saintpaulia sp. & SILVEIRA et al. (1986) \\
\hline & Sinningia speciosa & CESNIK (1959) \\
\hline & Tibouchina sp. & HUANG et al. (1982) \\
\hline
\end{tabular}




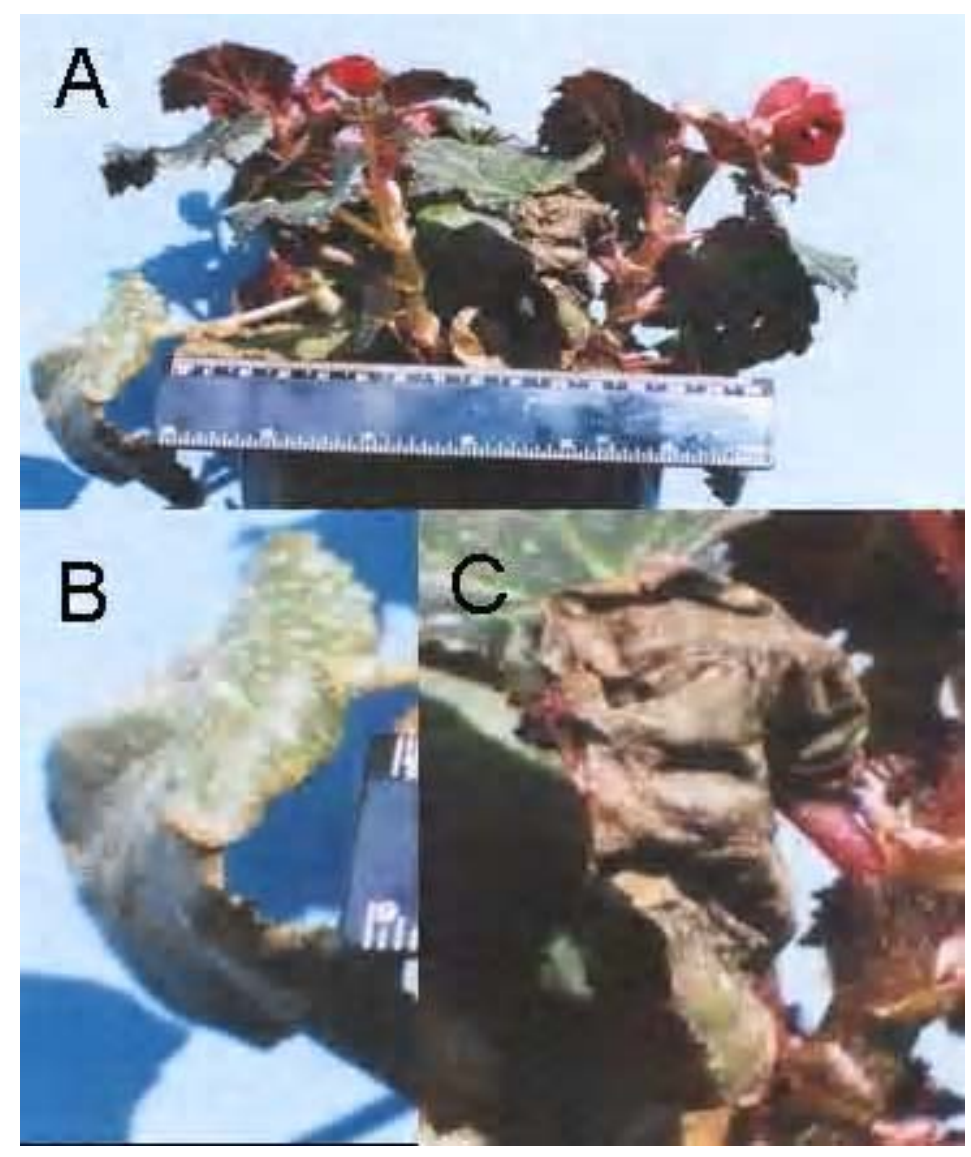

Figura 1. Aphelenchoides ritzemabosi em begônia. A: Aspecto de uma planta infectada. B: Detalhe de lesões pardo-escuras nas bordas das folhas. C: detalhe de necroses no limbo foliar.

Figure 1. Aphelenchoides ritzemabosi on begonia. A: plant infected. B: dark brown lesions on leaf margins. C: necrotic lesions on leaves. 